\title{
AMINO ACID SEQUENCE HOMOLOGY BETWEEN A SERINE PROTEASE INHIBITOR FROM BARLEY AND POTATO INHIBITOR I
}

\author{
by \\ IB SVENDSEN and IB JONASSEN \\ Carlsberg Laboratory, Department of Chemistry \\ and Carlsberg Research Laboratory, Department of Biotechnology, \\ Gamle Carlsberg Vej 10, DK-2500 Copenhagen Valby \\ and \\ JØRN HEJGAARD and SIGURD BOISEN \\ Department of Biochemistry and Nutrition \\ Technical University of Denmark, DK-2800 Lyngby
}

Keywords: Hiproly barley, chymotrypsin, subtilisin, immunoelectrophoresis

\begin{abstract}
A lysine-rich serine protease inhibitor, isolated from barley (H. vulgare, var. Hiproly) which inhibits subtilisin strongly, chymotrypsin weaker, but not trypsin, is shown to be homologous with potato inhibitor I (Richardson and Cossins, FEBS Lett. 52, 161 (1975)) (45\% of the amino acids in identical positions). The barley inhibitor seems to be the first example described of a protease inhibitor from higher plants in which the structure and reactive site is not stabilized by disulfide bonds.
\end{abstract}

\section{INTRODUCTION}

Several chromatographic and electrophoretic studies have shown that increased content of a few major lysine-rich albumin/globulin components is the primary source of the high lysine content in Hiproly barley (for references, see 14). Recently, two of these proteins, termed SP II A and SP II B, respectively, were purified and characterized $(7,8)$ including determination of their primary structure (19). The smallest component, SP II B, consists of 72 amino acid residues and has a molecular weight of 8072 . The larger peptide, SP II A (MW 9128), has the same amino acid sequence, except that the peptide chain is 11 residues longer at the $\mathrm{N}$ terminus.

Abbreviations: ATEE = acetyltyrosin ethyl ester; SDS = sodium dodecyl sulfate; TAME = tosylarginine methyl ester. 
In a parallel study, a 4-7 fold increased content of four different water/salt-soluble proteins compared to what is found in ordinary barley varieties was found to be closely associated with the high-lysine character of Hiproly barley (5). Among these proteins were identified two immunochemically different inhibitors of chymotrypsin and microbial serine proteases, termed CI-1 and CI-2. Purification and characterization of these protease inhibitors (2) showed that the SP II proteins and type CI-2 isoinhibitors had very similar size and amino acid composition.

The purposes of the present communication are 1) to document that the SP II proteins are immunochemically identical with the CI-2 type inhibitors, 2) to confirm the inhibitory properties of the SP II proteins and 3) to discuss their amino acid sequences in the light of this biological function, especially the striking homology of the barley inhibitors with the well characterized potato inhibitor I (13).

\section{MATERIALS AND METHODS}

\subsection{Materials}

Proteins SP II A and SP II B were isolated from $\mathrm{H}$. vulgare var. Hiproly as described in a previous communication (7). Isoinhibitors of type CI- 2 were isolated from the same barley line (2). A crude preparation of protease inhibitors from the potato variety Maritta (9) was obtained from Dr. L. C. BruhN. Subtilisin Novo, subtilisin Carlsberg and porcine chymotrypsin were gifts from Novo Industry, Copenhagen. Trypsin was obtained from Worthington, New Jersey, USA. Acetyltyrosine ethyl ester (ATEE) and tosyl-arginine methyl ester (TAME) were products of Sigma, St. Louis, USA. $\mathrm{N}$-trans-cinnamoylimidazole was obtained from Fluka, Buchs, Switzerland.

\subsection{Methods}

\subsubsection{Inhibition studies in the $\mathrm{pH}$-stat}

Inhibition of subtilisin, chymotrypsin and trypsin by the SP II A and SP II B proteins was studied in a Radiometer pH-stat composed of a titrator TTT 2 and a titrigraph SBR 2b. As substrates for subtilisin and chymotrypsin were used $5 \mathrm{ml}$ of ATEE $(25 \mathrm{~mm})$ and for trypsin $5 \mathrm{ml}$ of TAME ( $25 \mathrm{~mm})$. The liberation of hydrogen ions was followed by titration with $0.1 \mathrm{M}-\mathrm{NaOH}$ at $\mathrm{pH} 8.0$ and room-temperature. Increasing amounts of SP II A or SP II B were added to a series of $0.1 \%$ enzyme solutions $(100 \mu$ leach). From these mixtures suitable aliquots were withdrawn and added to the substrate solution in the $\mathrm{pH}$-stat. The degree of inhibition was calculated from the initial rates and due corrections made for dilution of enzyme by the addition of increasing volumes of SP II A or SP II $B$. The operational normality of the subtilisins and chymotrypsin was determined by active site titration with $\mathrm{N}$-trans-cinnamoylimidazole (18).

\subsubsection{Gelfiltration and SDS-gel electrophoresis of protease-inhibitor complexes}

Complexes between inhibitor SP II A or B and chymotrypsin, subtilisin Carlsberg and subtilisin Novo, respectively, were made by dissolving 1 $\mathrm{mg}$ of inhibitor and $1 \mathrm{mg}$ of protease in $500 \mu \mathrm{l}$ $50 \mathrm{~mm}$-Tris/ $\mathrm{HCl}$ buffer, $\mathrm{pH}$ 8. The mixtures were applied on a Sephadex G75 column $(0.9 \times$ $28 \mathrm{~cm}$ ) equilibrated with $0.1 \mathrm{M}-\mathrm{NH}_{4} \mathrm{HCO}_{3}$ and eluted with the same buffer. One $\mathrm{ml}$ fractions were collected with a flow-rate of $6 \mathrm{ml} \cdot$ hour ${ }^{-1}$. The first peak eluted corresponded to the enzyme-inhibitor complex and aliquots were removed, freeze-dried and used for SDS-gel electrophoresis.

The gel electrophoretic system used consisted of a one mm thick gel slab containing a 7.5$15 \%$ gradient of polyacrylamide as described by Chua and Bennoun (4). The aliquots of enzymeinhibitor complexes were dissolved in $0.1 \mathrm{M}$ $\mathrm{HCl}$, dried by evaporation and then processed as described (4).

\subsubsection{Immunoelectrophoresis}

Preparation of antibodies towards the different purified and polymerized barley proteins, as well as experimental conditions for rocket immunoelectrophoresis have been described in detail previously $(2,7)$.

\section{RESULTS AND DISCUSSION}

\subsection{Immunoelectrophoresis}

Rocket immunoelectrophoresis of SP II proteins and CI-2 inhibitors using antibodies raised against the SP II proteins or against the 


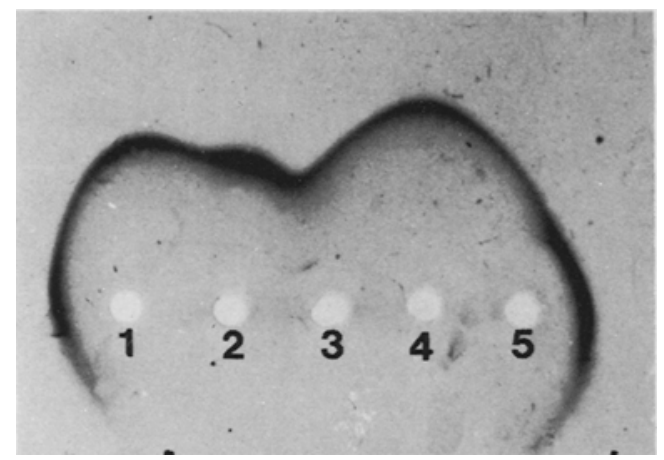

Figure 1. Immunoelectrophoretic comparison of SP II proteins and $\mathrm{Cl}-2$ protease inhibitors.

The proteins SP II A and SP II B (7) were applied in sample wells 2 and 4 , respectively. The inhibitor preparations CI-2a, CI-2b and CI-2c (2) in wells 1, 3 and 5 , respectively. In each well about $5 \mu \mathrm{g}$ antigen was applied in $5 \mu \mathrm{l}$ immunoelectrophoresis buffer. Antibodies towards the SP II proteins were used, but identical results were obtained with antibodies towards the purified inhibitors. Anode is shown at top. inhibitors showed immunoelectrophoretic identity between all the different protein preparations (Figure 1). These results strongly suggest that the SP II proteins belong to the type CI-2 protease inhibitors. Comparison of molecular weights and isoelectric points indicates that the proteins SP II A and SP II B correspond to the inhibitor forms CI-2b and CI-2c, respectively $(2,7)$.

\subsection{Inhibition experiments}

In order to confirm the inhibitory action and to test the specificity of the SP II A and SP II B proteins a series of inhibition studies was carried out using the $\mathrm{pH}$-stat technique. Although the SP II B protein is identical with the SP II A protein apart from 11 residues at the $\mathrm{N}$-terminus both were investigated with respect to inhibitory action, since the possibility existed that the inhibitory function was modulated by the $\mathrm{N}$ terminal part of the molecule and hence would be different in the two components.

The inhibition of subtilisin, chymotrypsin and trypsin by the SP II A and SP II B proteins is shown in Figure $2 \mathrm{~A}$ and $\mathrm{B}$. Both subtilisin

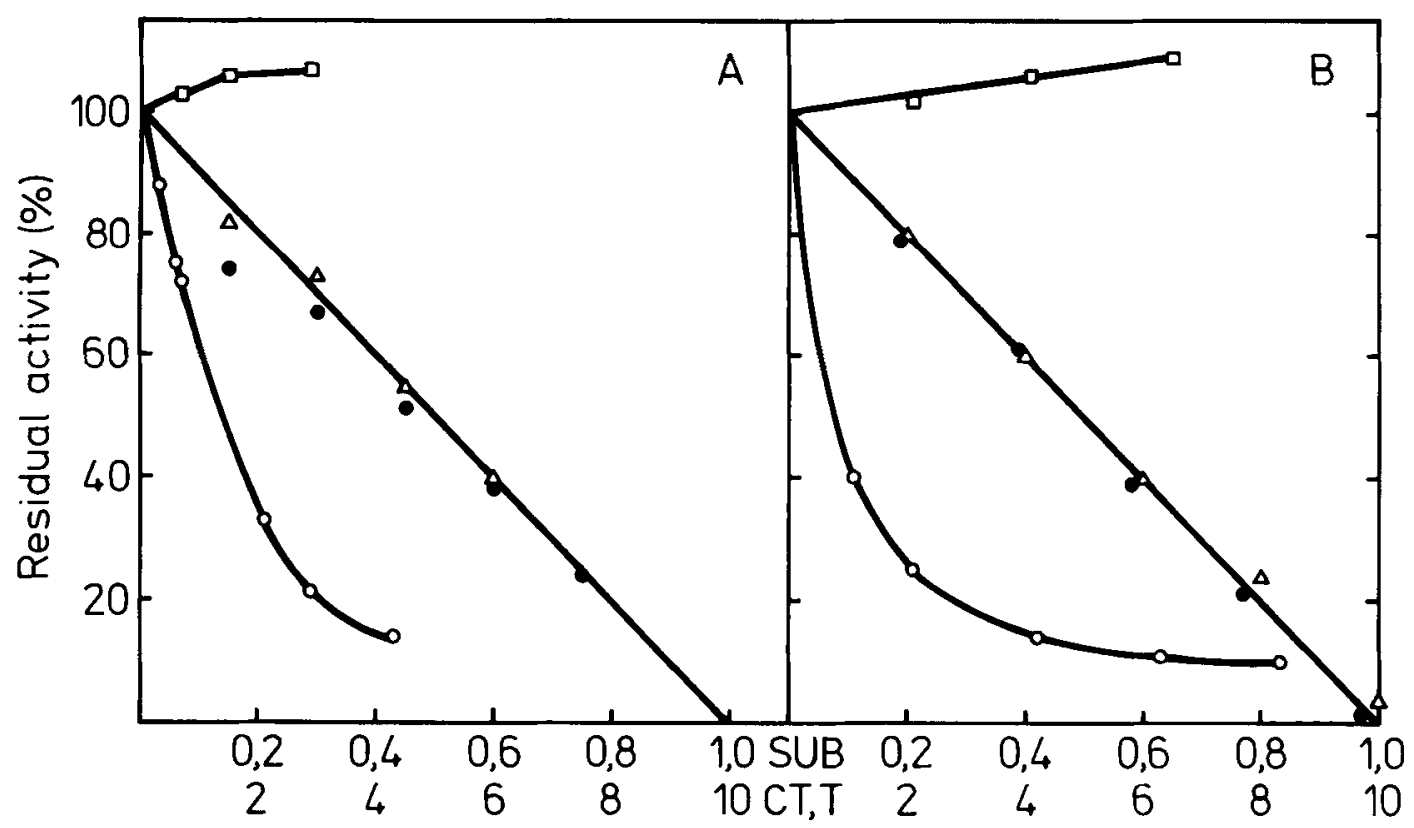

Figure 2. Inhibition of serine proteases by A) Protein SP II A. B) Protein SP II B.

Ordinate: residual activity. Abscisse: inhibitor/enzyme ratios (mole/mole). SUB = subtilisin Carlsberg (--) and Novo $(-\Delta-), C T=$ chymotrypsin $\left(-O_{-}\right)$and $T=\operatorname{trypsin}(-\square-)$. pH 8.0, room temperature. For further details see text. 
Carlsberg and subtilisin Novo were strongly inhibited by the SP II A and SP II B proteins. A linear relationship was obtained between the degree of inhibition and added amounts of inhibitor. Extrapolation to complete inhibition shows that the subtilisins were bound in a ratio of $1: 1$ to both inhibitors.

Chymotrypsin was not inhibited as strongly as the subtilisins by these inhibitors. A 4 to 8fold increase in inhibitor concentration over that of the enzyme only led to about $90 \%$ inhibition of chymotrypsin (Figure $2 \mathrm{~A}$ and B).

Trypsin was not inhibited by either of the inhibitors in the concentrations used (Figure $2 \mathrm{~A}$ and B). Due to shortage of inhibitor it was not possible to increase the concentration further. No

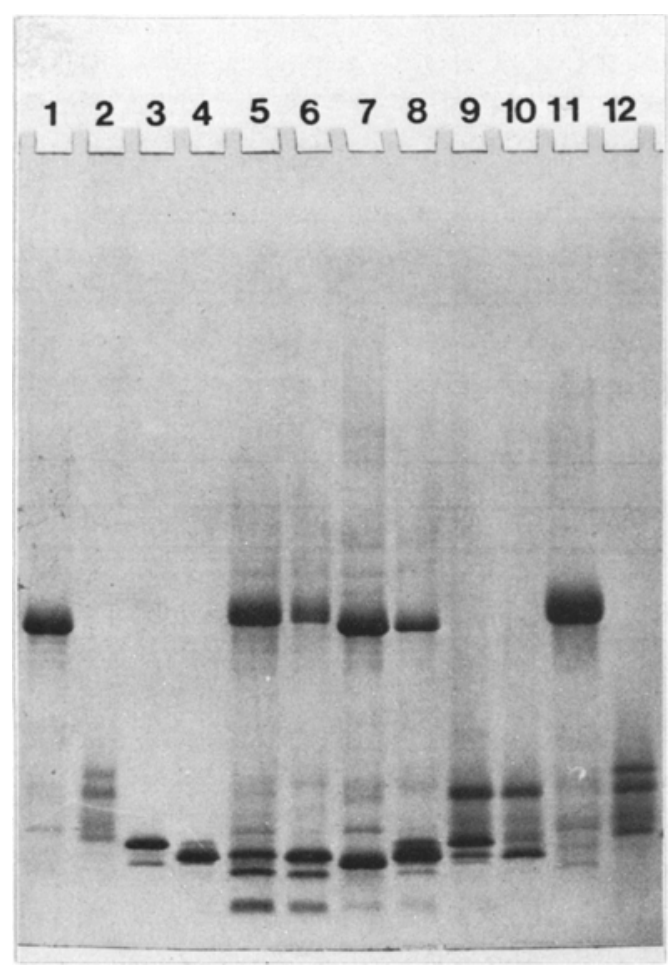

Figure 3. SDS-polyacrylamide gel electrophoresis of inhibitor-protease complexes.

Lane 1: subtilisin Novo, 2: chymotrypsin, 3: SP II A, 4: SP II B, 5: subtilisin Carlsberg-SP II A complex, 6: subtilisin Carlsberg-SP II B complex, 7: subtilisin Novo-SP Il A complex, 8: subtilisin NovoSP II B complex, 9: chymotrypsin-SP II A complex, 10: chymotrypsin-SP II B complex, 11: subtilisin Carlsberg, 12: chymotrypsin. explanation can at present be given for the apparent slight increase in tryptic activity upon addition of the SP II A or SP II B proteins.

The SP II inhibitors resemble inhibitor I isolated from potatoes in their inhibitory activities against the subtilisins and chymotrypsin. However, the potato inhibitor is also an inhibitor of trypsin (13).

\subsection{SDS-gel electrophoresis of proteinase- inhibitor complexes}

In order to gain some insight into the mechanism of the inhibitory action, SDS-gel electrophoresis was made on the denatured enzyme-inhibitor complex. As seen from Figure 3 no changes were observed in the electrophoretic mobility of the SP II A and SP II B proteins after interaction with chymotrypsin. Thus, under the conditions used, very little of the inhibitor with a hydrolyzed peptide bond in the active site was formed (11). However, if the subtilisin-inhibitor complexes are considered, two changes were noted. The mobility of SP II A had changed to that of the smaller molecule SP II $B$ indicating that a small peptide has been released by the enzyme, probably at the $\mathrm{N}$ terminal residues. Furthermore, two bands of smaller molecular weight appeared with both subtilisins vs. both inhibitors, but in largest amounts with the Carlsberg enzyme. These bands may represent products of the cleavage expected at the active site of the inhibitor.

\subsection{Sequence comparison between the SP II proteins and inhibitor I from potato}

MelviLle and Ryan (13) have isolated an inhibitor from potatoes which strongly inhibits chymotrypsin, subtilisin, and to some extent, trypsin. This inhibitor occurs as a tetramer composed of very similar genetic variants of the same subunit structure. These subunits have been sequenced and shown to consist of 70-71 residues $(16,17)$. Earlier studies $(2,10,15)$ have indicated that barley inhibitors of microbial alkaline proteases and chymotrypsin are similar to this potato inhibitor I with respect to chemical and inhibitory properties.

When the amino acid sequences of the SP II proteins are compared with the monomers of 


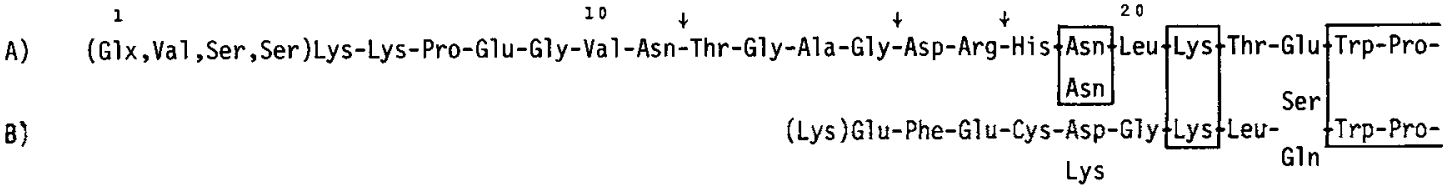

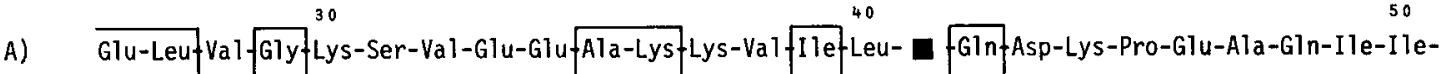

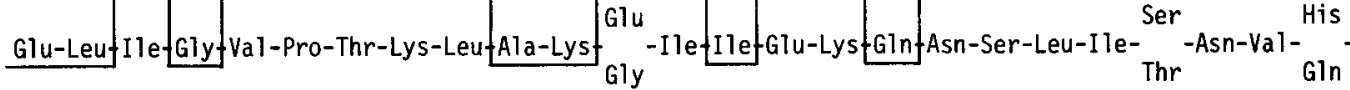

B)

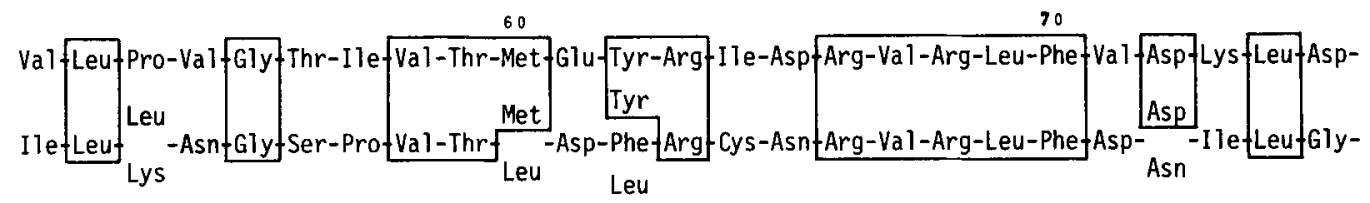

A)

B)

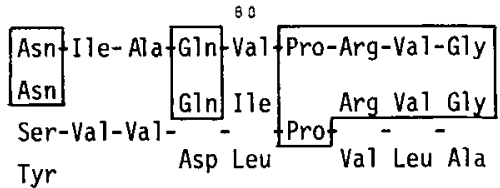

Figure 4. Comparison of the amino acid sequences of proteins SP II A and B with that of potato inhibitor I.

A) Sequence of SP II A. The actual position of the first four residues is not known due to a blocked $\mathrm{N}$ terminus. SP II B consists of three chains starting with Thr-11, Asp-16, and His-18, respectively, which are degradation products of SP II A (bonds hydrolyzed indicated by 1). B) Sequences of potato inhibitor I protomers $(16,17)$. Identical residues in the two sets of sequences are boxed. $\mathbf{0}$ : a gap inserted in position 41 of the SP II sequence in order to obtain maximum homology.

inhibitor I from potato (17) a striking homology is observed. This is shown in Figure 4, in which the two sets of sequences are aligned so that maximal homology is obtained which necessitates a gap in the SP II sequence in position 41.32 amino acids occur in identical positions in the two sets of sequences, provided the $»$ correct $\ll$ one is chosen in those positions where polymorphism is observed in the potato inhibitor. If one base mutation in the triplet codon is considered, the similarity in the sequences is even more evident. In this case 54 of the amino acid residues in the potato inhibitor match those of the SP II from barley.

It has been suggested by RICHARDSON and Cossins (17) that the active site of the potato inhibitor includes Met (47) - Asp (48) (Met (60) - Asp (61) in Figure 4), since limited proteolysis with chymotrypsin give rise to hydrolysis of this bond only. The high degree of homology found in the sequence Val (58) to Phe (70) in SP II, is compatible with the active site of SP II being located in this segment.
While the homology between the two inhibitors extends all the way to the C-terminus a marked difference is noted in the $\mathrm{N}$-terminal sequences. As seen in Figure 4, the sequence of the barley inhibitor SP II A extends 13-14 residues further than the potato isoinhibitors.

In the purification of the SP II proteins two active polypeptides were isolated which differed in amino acid composition and isoelectric points (7). One of these, SP II A, had a blocked Nterminus and had the sequence shown in Figure 4. The other component, SP II B, proved to be a degradation product of SP II A, and sequencing showed that it had a »ragged" N-terminus. As indicated in Figure 4 by vertical arrows, hydrolysis had taken place at three positions. That a similar hydrolysis has taken place with the potato isoinhibitors is indicated by the finding that the sequences start either with a lysine or a glutamic acid. »Ragged « N-terminals appear to be quite common among inhibitors as shown f. ex. with Bowman-Birk type inhibitors isolated from soy beans (6). It is uncertain 


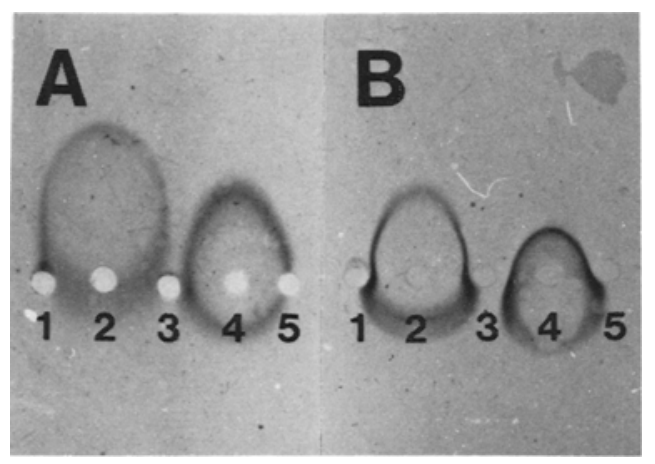

Figure 5. Immunoelectrophoretic comparison of protease inhibitors from barley and potato.

About $5 \mu \mathrm{g}$ of the barley inhibitor preparations CI-2a and CI-2b were applied in wells 2 and 4 , respectively. About 50, 10 and $2 \mu \mathrm{g}$ crude potato protease inhibitor (9) was applied in wells 1,3 and 5. Antibodies towards the SP II proteins (A) or the Cl-2 inhibitors (B) were used. Anode is shown at top.

whether the barley inhibitor exists in the grain as a "ragged N-terminus « polypeptide or if the proteolytic digestion giving rise to the new $\mathrm{N}$ terminal is connected to the purification procedure.

In spite of the observed homology no immunoelectrophoretic relationships between barley and potato inhibitors could be detected in experiments with antibodies towards the barley inhibitors (Figure 5). Neither precipitate formation nor interference with precipitate formation by the barley inhibitors were seen.

A tentative classification of serine protease inhibitors on basis of sequence homology has recently been suggested by LASKOWSKI and KATO (11). The barley inhibitor is the second member to be included in the "potato inhibitor I family" on basis of sequence homology.

Generally the abundance of disulfide bonds has been assumed to be responsible for the resistance of protease inhibitors to denaturation and proteolytic degradation. Within each inhibitor family hitherto established the positions of all intra-chain disulfide bridges including the bridges of the reactive site loop are fully conserved (11). The lack of cystine in the barley inhibitor variants shows that the inhibitory properties and high stability towards heat and denaturing agents
(2) are only dependent on non-covalent stabilization of the tertiary structure in the spotato inhibitor I family«. This observation has also been made with proteinase A inhibitor 3 (1) and proteinase B inhibitors 1 and 2 (12) from yeast, but to our knowledge the present report demonstrates for the first time the absence of disulfide bridges in a protease inhibitor from higher plants. No direct investigation has yet been made of the $\alpha$-helix and $\beta$-pleated sheet content, but if Chou and Fasman's (3) rules for formation of tertiary structure is applied to the barley inhibitor a high content of $\alpha$-helix is to be expected.

The high degree of homology between inhibitors from Solanaceae and Gramineae suggests that the "potato inhibitor I family» is widely distributed in plants.

\section{ACKNOWLEDGEMENTS}

We wish to thank professor M. OTTESEN for critical review of the manuscript and Ms. IRENE SimONSEN for skilled technical assistance. Part of the work of S. BoISEN was supported by a grant to professor R. DJURTOFT and S. BoISEN from the Danish Council of Scientific and Industrial Research covering protease inhibitor studies in cereals.

\section{REFERENCES}

1. Biedermann, K., U. Montali, B. Martin, I. SVendsen \& M. Ottesen: The amino acid sequence of proteinase $A$ inhibitor 3 from baker's yeast. Carlsberg Res. Commun 45, 225235 (1980)

2. Boisen, S., C. Y. Andersen \& J. Hejgaard: Inhibitors of microbial serine proteases and chymotrypsin in barley grains. Isolation, partial characterization and immunochemical relationships of multiple molecular forms. In press.

3. Chou, P. Y. \& G. D. Fasman: Prediction of the secondary structure of proteins from their amino acid sequence. Adv. Enzymol., A. Meister, ed., J. Wiley and Sons, 47, 45 (1978)

4. Chua, N.-H. \& P. Bennoun: Thylakoid membrane polypeptides of Chlamydomonas reinhardtii: Wild type and mutant strains deficient in photosystem II reaction center. Proc. Nat. Acad. Sci. US 72, 2175-2179(1975) 
5. Hejgaard, J. \& S. Boisen: High-lysine proteins in Hiproly barley breeding: Identification, nutritional significance and new screening methods. Hereditas 93, 311-320 (1980)

6. Hwang, D. L.-R., K.-T. D. Lin, W.-K. Yang \& D. E. Foard: Purification, partial characterization, and immunological relationships of multiple low molecular weight protease inhibitors of soybean. Biochim. Biophys. Acta 495, 369-382 (1977)

7. JoNASSEN, I.: Characteristics of Hiproly barley I. Isolation and characterization of two watersoluble high-lysine proteins. Carlsberg Res. Commun. 4.5, 47-58 (1980)

8. JONASSEN, I.: Characteristics of Hiproly barley II. Quantification of two proteins contributing to its high lysine content. Carlsberg Res. Commun. 45, 59-68 (1980)

9. Kaiser, K.-P., L. C. Bruhn \& H.-D. Beutz: Proteinaseinhibitors in potatoes. Protein-, trypsin- and chymotrypsininhibitor patterns by isoelectric focusing in polyacrylamide gel. A rapid method for identification of potato varieties. Z. Lebensm. Unters.-Forsch. 154, 339-347 (1974)

10. KIRSI, M.: Proteinase inhibitors in germinating barley embryos. Physiol. Plant. 32, 89-93 (1974)

11. Laskowsks, M. Jr., \& I. Kato: Protein inhibitors of proteinases. Ann. Rev. Biochem. 49. 593-626 (1980)

12. Maier, H., H. Müller, R. Tesch, I. Witt \& H.
Holzer: Amino acid sequence of yeast proteinase B inhibitor 1. Comparison with inhibitor 2. Biochem. Biophys. Res. Commun. 91, 13901398 (1979)

13. Melville, J. C. \& C. A. Ryan: Chymotrypsin inhibitor I from potatoes. J. Biol. Chem. 247, 3445-3453 (1972)

14. Mifuin, B. J. \& P. R. Shewry: The synthesis of proteins in normal and high lysine barley seeds. In: Recent advances in the biochemistry of cereals. D. L. Laidman \& R. G. Wyn Jones, eds., Academic Press London, pp. 239-273 (1979)

15. Mikola. J. \& E.-M. Suolinna: Purification and properties of an inhibitor of microbial alkaline proteinases from barley. Arch. Biochem. Biophys. 144, 566-575, (1971)

16. Richardson, M.: Chymotryptic inhibitor I from potatoes. The amino acid sequence of subunit $A$. Biochem. J. 137, 101-112 (1974)

17. Richardson, M. \& L. Cossins: Chymotryptic inhibitor I from potatoes: The amino acid sequences of Subunits B, C and D. FEBS Lett. 45, 11-13 (1974). (Corrigendum in FEBS Lett. $52,161(1975))$

18. Schonbaum, G. R., B. Zerner \& M. L. Bender: The spectroscopic determination of the operational normality of an a-chymotrypsin. J. Biol. Chem. 236, 2930-2934 (1961)

19. Svendsen, I., B. Martin \& I. Jonassen: Characteristics of Hiproly barley III. Amino acid sequences of two lysine-rich proteins. Carlsberg Res. Commun. 45, 79-85 (1980) 